discharge planning visits with appropriate members of team allowing patient to tell their story only once, more timely discharge. It releases time to care for RGNs who have social work support team available as resource.

Conclusion By empowering experienced staff member who has a sound knowledge base of palliative care and the introduction of new skills and training, patients have services readily accessible to them. The specialist palliative care social worker is now able to concentrate on complex issues whilst being supported from a more knowledgeable team than before.

\section{P-221 HOW DOES END OF LIFE CARE AND THE VIEWS OF STAKEHOLDERS FIT WITH THE AMBITIONS OF NATIONAL POLICY?}

${ }^{1}$ Rhiannon Barker, ${ }^{1}$ Patricia Wilson, ${ }^{2}$ Claire Butler. ${ }^{1}$ Centre for Health Service Studies, University of Kent, Canterbury, UK; ${ }^{2}$ University of Kent and Wisdom Hospice, Medway Community Healthcare, Kent, UK

10.1136/bmjspcare-2018-hospiceabs. 246

Background Whilst a string of strategy reports (Department of Health, 2008) over the last decade have laid out aspirations for good care, responsive to individual needs and preferences, at the end of life, Care Quality Commission (2016) data reveals huge variability in provision. Inequities relating to geography, age, ethnic group, geographical area and disease/ condition are frequently reported (House of Commons Health Committee, 2015).

Aims There are a paucity of studies looking at how national policy in end of life care helps to shape local practice both in relation to allocation of resources and attempts to improve national consistency in end of life provision. This study will ask if national policy is effective in helping to surmount the system challenges confronted in delivering an effective end of life service and whether the aspirations of policy fit with the views of patients, carers, clinicians and managers.

Methods Phase 1: Scoping study. Literature review and semistructured interviews with a sample of professionals from the statutory and non-statutory sector who have been influential in shaping current policy. The purpose of these interviews is to help identify and map key challenges in end of life care, to shed light on how policy has evolved and how it supports and guides practice. Phase 2: Case studies in three Clinical Commissioning Groups to interrogate how end of life care is rolled out at a local level.

Results This presentation will discuss results of the ongoing scoping study due to be completed by August 2018 .

Conclusions It is anticipated that this poster will generate important conversations that will inform the direction of Phase 2 of the $\mathrm{PhD}$. Key recommendations will be provided for professionals and policy makers that will feed into the debate concerning how end of life policy and guidance at can contribute to achieving more equitable and consistent end of life care.

\section{P-222 TIMELY SUPPORT FOR CARERS OF PEOPLE AT THE END OF LIFE THROUGH THE ADULT CARER SUPPORT PLAN}

Emma Carduff, Susan Swan, Richard Meade. Marie Curie, Glasgow, UK

10.1136/bmjspcare-2018-hospiceabs.247
Introduction The Carers (Scotland) Act (2016) places a duty on local authorities to prepare an Adult Carer Support Plan (ACSP) and Young Carer Statement for any carer who requests one, or is identified as such. From 2019, this will be assisted by a fast track process for carers of people in their last six months of life. Timely identification of unpaid carers, assessment and support can; reduce the overwhelming pressure of caregiving, increase competence, confidence, satisfaction and the quality of the care given.

Aim To provide evidence on the supportive needs of carers to inform recommendations regarding the timescale for the creation of fast tracked ACSPs under the Carers (Scotland) Act (2016).

Methods The study triangulated data from a literature review, qualitative secondary analysis ( $n=19$ interviews; three focus groups) and two primary focus groups with bereaved carers $(\mathrm{n}=11)$.

Results Themes included; barriers to and triggers for identification and needs including physical support, psychological support, respite, information, communication, co-ordination and competing demands. Additional themes were speed of decline and end of life care.

Conclusion Health and social care professionals need to take a radical, reactive move to presume that every patient has a carer, and ensure they understand their entitlements. Carer identification is everyone's responsibility and it should be the ambition of the Carer (Scotland) Act (2016) that this happens early in the illness trajectory. In so doing, rapid assessment and support can be initiated to help carers navigate and cope with an uncertain, often rapidly deteriorating illness trajectory.

\section{P-223 MODERN MATRON IN PALLIATIVE AND END OF LIFE CARE: LINKING CLINICAL STRATEGY TO DAY-TO-DAY CARE}

${ }^{1}$ Kim Bonnar, ${ }^{1}$ Rachel Ainscough, ${ }^{2}$ Eleanor Grogan, ${ }^{3}$ Audrey Rowe, ${ }^{3}$ Karen Torley, ${ }^{2}$ Paul Paes. ${ }^{1}$ Marie Curie, London, UK; ${ }^{2}$ Northumbria Healthcare NHS Foundation Trust, Morpeth, UK; ${ }^{3}$ Marie Curie, Newcastle, UK

\subsection{6/bmjspcare-2018-hospiceabs.248}

Background When first introduced, the Modern Matron role was designed to have authority on leading on clinical strategy and governance, while also being an active presence on wards and in communities (Department of Health, 2000).

Aim As part of a wider partnership that established a multisite palliative care hospital liaison team and a rapid response service, an innovative NHS Foundation Trust and a leading charity identified that a Modern Matron in Palliative and End of Life Care could support a joint strategy to improve care locally.

Method Several studies indicate variation in how Modern Matron roles are implemented in different areas (Savage \& Scott, 2004; Read, Ashman, Scott et al., 2004). As the role is untested within a palliative care context, this work aims to better understand how this role works in practice. To explore this, an in-depth, case study interview was conducted with the Modern Matron in Palliative and End of Life Care.

Results Thematic analysis identified three priorities for the role:

- Linking strategy to day-to-day delivery through clinical leadership

- Creating a seamless service between hospital and community

- Value in partnership working. 
Further, the Modern Matron is working to build nursing teams' confidence in taking appropriate risk to enable improved patient outcomes.

Conclusion The interview indicates that using clinical leadership skills to create tangible links between strategy and day-today practice, and bridging care between hospital and community are key priorities for the Modern Matron for Palliative and End of Life Care role. The impact will be explored further in a future evaluation of the wider partnership.

\section{P-224 THE VALUE OF HOSPICES IN NORTH WALES A COLLABORATION BETWEEN ACADEMIA AND THIRD SECTOR ORGANISATIONS}

${ }^{1}$ Nicole Hughes, 'Jane Noyes, ${ }^{1}$ Carys Jones, ${ }^{2}$ Trystan Pritchard. 'Bangor University, Bangor, UK; 'St David's Hospice, Llandudno, UK

10.1136/bmjspcare-2018-hospiceabs.249

Background In a difficult financial climate, hospices need to reaffirm their impact and contribution to society. Evaluating the externalities associated with the hospice services provided and alternative models of care will inform resource allocation. This partial economic analysis is being undertaken as a component of a larger study utilising a Social Return on Investment framework (SROI) to investigate the social, economic and environmental impact of hospice services.

Aim The aim is twofold; to estimate the costs per inpatient bed day for those nearing end of life to inform an analysis of how patient disease and health system related factors influence resource allocation and costs. Secondly, to demonstrate how the costs associated with the day care and inpatient units differ across alternative models of care.

Method A partial economic analysis will be performed as part of a multi-site comparative study of four hospices across North Wales, with the focus placed on the inpatient and day care units. Anonymised patient level data from each hospice will be accessed retrospectively and used in conjunction with the hospices' annual accounts for October 2016. Hospice costs will be estimated using a bottom-up approach which will demonstrate the use of detailed activity and input usage data from records at the service provider level to estimate unit costs. This approach will also help to capture the site level differences.

Results The results are pending as the study is still being undertaken at time of abstract submission.

\section{P-225 ENABLING COMPREHENSIVE PERSON-CENTRED SUPPORT FOR FAMILY CARERS OF PEOPLE WITH MOTOR NEURONE DISEASE}

${ }^{1}$ Gail Ewing, ${ }^{2}$ Sarah Croke, ${ }^{2}$ Christine Rowland, ${ }^{2}$ Gunn Grande. ' University of Cambridge, Cambridge, UK; ${ }^{2}$ University of Manchester, Manchester, UK

\subsection{6/bmjspcare-2018-hospiceabs. 250}

Background Motor Neurone Disease (MND) is a life-shortening condition with no cure. Consequently, hospice and palliative care are recommended from diagnosis. Family carers provide vital support for people with MND but caregiving can be very physically and mentally demanding. It is therefore crucial to ensure healthcare practitioners (HCPs) can provide timely support to carers fitting their individual needs. Currently there are no UK interventions for this.

Aim To adapt an existing Carer Support Needs Assessment Tool (CSNAT) intervention for comprehensive person-centred carer to support the needs and situation of family carers of people with MND.

Methods Stages:

1. Focus groups and interviews with 33 carers (14 bereaved, 19 current carers) to capture their self-defined needs, key points of change during patient's illness, and main support services.

2. Workshops with HCPs $(\mathrm{N}=22)$ and carer advisors $(\mathrm{N}=19)$ to inform materials and procedures for MND carer assessment and support.

Results Stage 1: Carers' experience was one of dealing with a devastating diagnosis, a constantly changing situation with heavy dependence on them as carers, and with little consideration of their separate support needs. Carers' support needs mainly mapped onto CSNAT domains, but some MND carers experienced relationship issues warranting further consideration. Stage 2 (on-going) will review carer advice on the need for a further CSNAT domain to address relationship issues; HCP and carers' views obtained at workshop discussions explore when, where, how and by whom MND carer assessment and support should best be provided in a practice context.

Conclusions Study findings will provide insights into how MND carers want to be assessed and supported and how HCPs felt this approach could be delivered in practice. Understandings obtained from Stages 1 and 2 will form the basis for an intervention to be tested in a future Stage 3 feasibility study.

\section{The workforce and workplace}

\section{P-226 REVIEW OF A GP FELLOWSHIP SCHEME IN PALLIATIVE MEDICINE}

${ }^{1,2}$ Rebecca Thompson, ${ }^{1}$ Karen Chumbley, ${ }^{1,3}$ Jennie Stemp. 'St Helena Hospice, Colchester, UK; ${ }^{2}$ Ardleigh Surgery, Ardleigh, UK; ${ }^{3}$ Parsons Heath Medical Centre, Colchester, UK

\subsection{6/bmjspcare-2018-hospiceabs.251}

Background End of life care is a core part of General Practice yet there is often little formal palliative care training for GPs (Barclay, Todd, Lipscombe, 1997) emphasising the need for improved training and collaboration between Primary Care and Palliative Care services.

North East Essex with the support of the East of England Deanery established a Post CCT (certificate of completion of training) Fellowship Scheme offering education within a subspeciality. Two posts were created in specialist Palliative Medicine. Similar schemes have shown improvement in patient management (Duckett \&Casserly, 2003).

Aims

- Improve recruitment and retention of GPs within the local area (Marchand \& Peckham, 2017)

- Improve palliative care expertise in Primary care (Mitchell, 2002)

- GP development and education (Shipman, Addington-Hall, Barclay et al., 2001)

- Promote collaborative working between Primary care and Palliative Medicine. 